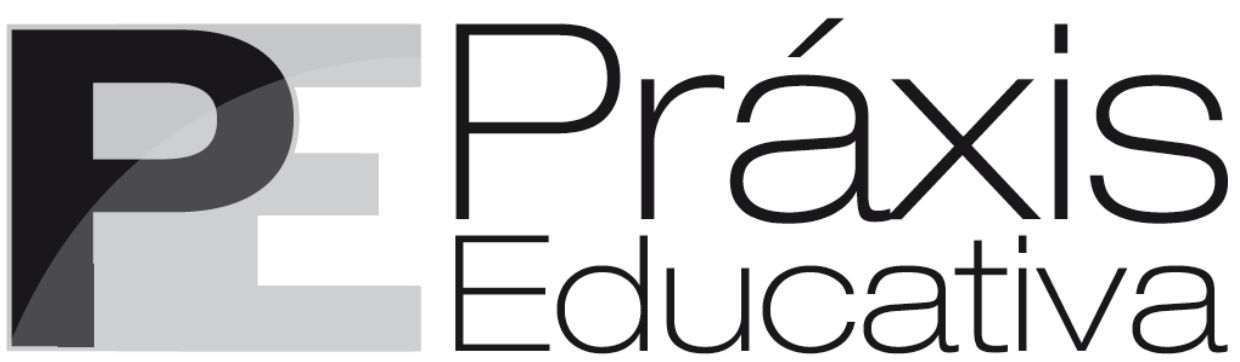

ISSN 1809-4309 (Versão online) DOI: 10.5212/PraxEduc.v.11i3.0016

\title{
Avaliação e Currículo na Educação Básica: a especificidade da Educação Infantil
}

\section{Evaluation and Curriculum in Basic Education: the specificity of early Childhood Education}

\section{Evaluación y Currículo en la Educación Básica: la especificidad de la Educación Infantil}

\author{
Maria Nilceia Andrade Vieira \\ Valdete Côco ${ }^{* *}$
}

\begin{abstract}
Resumo: Nas políticas públicas atuais, a avaliação e o currículo permanecem em pauta, provocando indagações e tensionando debates. Este artigo focaliza o campo da Educação Infantil (EI) reunindo discussões sobre a avaliação institucional e o currículo nessa etapa inicial da Educação Básica. Consideram-se como aportes teórico-metodológicos referenciais bakhtinianos e a abordagem do ciclo de políticas de Ball em associação a produções acadêmicas referentes aos temas, com análise de documentos da legislação brasileira e de elementos advindos de pesquisa bibliográfica. Os resultados evidenciam que a sustentação teórica e o embasamento legal da EI, no que tange à avaliação e ao currículo, fortalecem um percurso de consolidação de seu pertencimento à Educação Básica, em simultaneidade à demarcação de sua especificidade.
\end{abstract}

Palavras-chave: Avaliação institucional. Currículo. Educação Infantil.

\begin{abstract}
In current public policies, evaluation and curriculum are still on the agenda, provoking inquiries and bringing tension to debates. This paper focuses on the Early Childhood Education (ECE) field, gathering discussions about institutional evaluation and curriculum at that initial phase of Basic Education. Bakhtinian references and the approach of Ball's policy cycle associated to academic productions related to the themes are seen as theoretical-methodological contributions, besides analysis of both Brazilian legislation documents and elements originated from bibliography research. The results demonstrate that theoretical sustentation and the ECE legal basis, in relation to evaluation and curriculum, strengthen a consolidation trajectory of its belongingness to Basic Education simultaneously to its specificity demarcation.
\end{abstract}

Keywords: Institutional evaluation. Curriculum. Early Childhood Education.

Resumen: En las políticas públicas actuales, la evaluación y el currículo siguen en la agenda, provocando preguntas y generando tensiones en los debates. Este artículo enfoca el tema de la Educación Infantil (EI)

\footnotetext{
* Pedagoga da Prefeitura Municipal de Vitória - ES. Professora do Curso de Pedagogia da Faculdade Estácio de Sá, Vila Velha - ES. E-mail: <nilceia_vilavelha@hotmail.com>.

** Professora da Universidade Federal do Espírito Santo (UFES). E-mail: <valdetecoco@hotmail.com>.
}

Práxis Educativa, Ponta Grossa, p. 812-831, v. 11, n. 3, set./dez. 2016 Disponível em: <http://www.revistas2.uepg.br/index.php/praxiseducativa> 
y reúne discusiones sobre la evaluación institucional y el currículo en esa etapa inicial de la Educación Básica. Se consideró como aportes teórico-metodológicos algunos referenciales de Bajtín y el abordaje del ciclo de políticas de Ball, asociados a producciones académicas relacionadas a los temas discutidos.También se analizó documentos de la legislación brasileña y elementos obtenidos desde de la investigación bibliográfica. Los resultados señalan que las bases teórica y legal de la EI, respecto a la evaluación y al currículo, fortalecen un recorrido de consolidación de su pertenencia a la Educación Básica, de forma simultánea a la definición de su especificidad.

Palabras clave: Evaluación institucional. Currículo. Educación Infantil.

\section{Introdução}

A avaliação educacional constitui tema polêmico, que provoca tensionamentos nos diferentes níveis e etapas da educação, seja relacionado à aprendizagem, à instituição, ao desempenho dos profissionais, seja às políticas públicas. Atualmente, a avaliação mantém-se na centralidade das políticas educacionais, sobretudo com a ampliação da realização de testes padronizados e em larga escala, impulsionando debates e promovendo estudos que analisam seus impactos sobre outras questões atinentes ao campo educacional, entre as quais o currículo.

Neste contexto, a Educação Infantil (EI), como primeira etapa da Educação Básica (BRASIL, 1996) insere-se, de forma cada vez mais consistente no diálogo acerca de questões ligadas à avaliação e, nesse movimento dialógico, emergem problematizações que também se dirigem às questões curriculares, situadas particularmente no campo do trabalho educativo com as crianças pequenas.Entendendo que a etapa inicial da Educação Básica integra a cadeia temática das discussões sobre avaliação e currículo, promovendo indagações que alteram concepções, proposições e encaminhamentos políticos, cabe destacar que a EI vem alcançando conquistas progressivas, que fortalecem seu reconhecimento social. Assinalamos um movimento de visibilidade da EI no cenário social, associado à produção de apontamentos legais como parte do movimento das políticas públicas que se efetivam no conjunto do desenvolvimento da educação nacional.

Nesse processo, consolidar seu pertencimento à Educação Básica, em especial com ações que demarquem sua especificidade, constitui um dos desafios da EI, inclusive no campo da avaliação e do currículo. Integrando esse desafio, com este texto perquirimos como a EI vem participando das discussões emergentes nessas pautas, considerando ser a única etapa do sistema educacional brasileiro em que não se efetivam políticas de avaliação com base em testes padronizados direcionados às crianças. Com isso, objetivamos compor a discussão acerca da avaliação institucional e do currículo na EI, no contexto das políticas públicas atuais e de sua recente trajetória como etapa inicial da Educação Básica.

Nesse propósito, primeiramente, como referência, tomamos a abordagem do ciclo de políticas $^{1}$ (BALL, 2001; MAINARDES; MARCONDES, 2009). Essa abordagem "enfatiza os processos micropolíticos e a ação dos profissionais que lidam com as políticas no nível local e indica a necessidade de se articularem os processos macro e micro na análise de políticas educacionais" (MAINARDES, 2006, p. 49). Consideramos de maior interesse, para as discussões a que nos propomos neste artigo, o contexto de produção de texto que Ball (2001) explicita como aquele em que as ações são formalizadas por meio de documentos oficiais, sendo relacionado à definição de políticas públicas.

\footnotetext{
1 A abordagem do ciclo de políticas considera os contextos de influência, de produção de texto e das práticas para compreender como as políticas são produzidas/elaboradas e efetivadas/vivenciadas (BALL, 2001; MAINARDES; MARCONDES, 2009; MAINARDES, 2006), problematizando as diversas interpretações dos sujeitos que atuam em seus distintos contextos.
}

Práxis Educativa, Ponta Grossa, p. 812-831, v. 11, n. 3, set./dez. 2016 Disponível em: <http://www.revistas2.uepg.br/index.php/praxiseducativa> 
Ao considerar a fragilidade de grande parte das políticas, Ball as destaca como "[...] produto de acordos, algo que pode ou não funcionar; elas são retrabalhadas, aperfeiçoadas, ensaiadas, crivadas de nuances e moduladas através de complexos processos de influência, produção e disseminação de textos e, em última análise, recriadas nos contextos da prática" (BALL, 2001, p. 102, grifo nosso). Assim, tomamos esta referência para evidenciar o movimento complexo que se estabelece na efetivação de políticas avaliativas e curriculares, especialmente quando observamos alguns pontos de contato entre essas duas pautas. Complexidade que envolve a participação de distintos interlocutores, com diferentes, e por vezes tensionantes, mensagens circulantes.

Nessa perspectiva,reconhecemos simultaneamente as singularidades que nos constituem,com base em nossas vivências, e a necessidade do outro para nossa constituição como sujeitos. Assim, associamos o referencial bakhtiniano (BAKHTIN, 2011) para evidenciar as múltiplas vozes que participam dessa dialogia. Vozes que, além de informar dissonâncias, disputam sentidos para as ações, buscam concordâncias e enunciam contrapalavras, uma vez que

\begin{abstract}
[...] cada enunciado é pleno de ecos e ressonâncias de outros enunciados com os quais está ligado pela identidade da esfera de comunicação discursiva. Cada enunciado deve ser visto antes de tudo como uma resposta aos enunciados precedentes de um determinado campo (aqui concebemos a palavra 'resposta' no sentido mais amplo): ela os rejeita, confirma, completa, baseia-se neles, subentende-os como conhecidos, de certo modo os leva em conta. (BAKHTIN, 2011, p. 297, grifo do autor).
\end{abstract}

Ancorados nesses referenciais, e inseridos no contexto de debates que circundam a avaliação e o currículo na EI no cenário das políticas educacionais, desenvolvemos nossas reflexões com base em três movimentos. Em um primeiro movimento, buscamos compor a ancoragem das questões sobre a avaliação e o currículo a partir da abordagem do ciclo de políticas (BALL, 2001; MAINARDES; MARCONDES, 2009). Focalizamos o contexto da produção de textos, no sentido de compreender o cenário atual, marcado pelas determinações de agências internacionais, ampliando perspectivas de análise quanto às tendências relacionadas à avaliação e ao currículo, que se configuram na Educação Básica, principalmente nos Ensinos Fundamental e Médio. Com esse arcabouço de referências, no segundo movimento, avançamos as reflexões para a trajetória da EI nesse contexto das políticas públicas produzidas em nosso país. Destacamos aportes legais como corpus de análise para o reconhecimento das lutas e conquistas desse percurso, em meio ao seu pertencimento à Educação Básica, com atenção especial à demarcação de sua singularidade. No terceiro movimento, abordamos as perspectivas e proposições que se apresentam no campo da avaliação institucional e do currículo na EI, considerando, principalmente, as discussões atuais que perpassam as temáticas, e articulando dados do contexto local do Espírito Santo. Por fim, elencamos as principais considerações que se constituem com a organização deste artigo, permitindo destacar que a fundamentação teórica e o embasamento legal da EI sustentam-se em uma perspectiva coletiva e participativa. Assim, no que tange à avaliação e ao currículo, essa perspectiva fortalece um percurso de consolidação de seu pertencimento à Educação Básica em simultaneidade à demarcação de sua especificidade.

\title{
Avaliação e currículo no contexto das políticas públicas brasileiras
}

Considerando o cenário atual, a centralidade da avaliação e do currículo, nas políticas educacionais e no contexto das políticas sociais mais amplas, tem sido pauta de estudos e pesquisas que anunciam tendências e perspectivas, e denunciam dificuldades e contradições, articulando a avaliação a questões que envolvem a gestão, o financiamento, a formação, e o currículo.

Desse modo, as tendências que acenam no horizonte das políticas públicas para a 
educação, no Brasil, têm sido demarcadas pela centralidade do capital e pelo foco em resultados, atendendo a determinações de organismos internacionais, como o Banco Mundial, a Organização para a Cooperação e Desenvolvimento Econômico (OCDE), o Banco Interamericano de Desenvolvimento (BID), entre outras. Essas exigências adentram as políticas educacionais no Brasil e demais países da América Latina, definindo prioridades e vertendo para uma lógica baseada na competição e na meritocracia entre governos, escolas e cidadãos. Nesse contexto influenciado por agências econômicas que priorizam a preparação de mão de obra para atender às leis de mercado, Ball (2004, p. 1.109) adverte que,

[...] cada vez mais, as políticas sociais e educacionais estão sendo articuladas e legitimadas explícita, direta e, muitas vezes, exclusivamente em função do seu papel em aumentar a competitividade econômica [...], desconsiderando compromissos de justiça social, equidade e tolerância e enaltecendo o espírito empresarial, a competição e a busca pela excelência.

Articulando essas assertivas ao conteúdo de relatórios mais atuais do Banco Mundial $(2013,2014)$, nossas análises indicam que as premissas desses documentos explicitam vinculações com o êxito, a eficácia, a mobilidade de mão de obra, a comparação dos dados entre os países, destacando o uso de ferramentas que auxiliem os países a avaliar e priorizar o que possibilita maior êxito nas políticas educacionais, por meio da Abordagem de Sistemas para Melhores Resultados em Educação (SABER, na sigla em inglês). "Entre as áreas de políticas que fazem parte do SABER, estão o desenvolvimento na primeira infância, a avaliação de alunos, o treinamento de professores, financiamento e o desenvolvimento da força de trabalho" (BANCO MUNDIAL, 2013, p. 13, grifos nossos).

Essa conjuntura convoca reflexões, debates e posicionamentos ante nossos princípios e ideologias, uma vez que presenciamos

[...] um desenvolvimento, sem precedentes, de uma série de especialistas e de entidades de acreditação e de avaliação que definem os currículos da formação de professores, o modo de entrada na profissão, as regras do período probatório e o juízo sobre os desempenhos profissionais. Estes especialistas são fortemente influenciados pelas organizações internacionais (União Europeia, OCDE, etc.) e tendem a ocupar um espaço que deveria ser dos professores mais experientes. (NÓVOA, 2011, p. 54-55, grifo nosso).

Tais pressupostos alinham-se à busca de lucro e acumulação de características do sistema capitalista e, portanto, como assinala Afonso (2013), há um estranhamento quando tentamos considerar como autêntica a intenção dessas organizações na melhoria dos níveis educacionais de países semiperiféricos, a não ser que esses índices permaneçam "[...] dentro dos limites que são desejados e necessários para a contínua expansão desse mesmo sistema capitalista mundial, [...] ou, mais genericamente, como condição para preparar e integrar novos consumidores no mercado mundial" (AFONSO, 2013, p. 279).

Compondo esse panorama e focalizando o contexto da Educação Básica ${ }^{2}$, importa assinalar a consolidação das avaliações externas ou em larga escala, com base em testes padronizados que protagonizam o cenário educacional brasileiro há mais de 20 anos, e ocupam lugar de destaque nas políticas instituídas pelo governo para esse nível de ensino.

\footnotetext{
${ }^{2}$ É importante situar que a organização da educação no Brasil, em dois níveis (Educação Básica e Ensino Superior), foi instituída pela LDB (BRASIL, 1996) e, nessa nova composição, a Educação Básica abarca três distintas etapas: a Educação Infantil, o Ensino Fundamental e o Ensino Médio.
} 
Quanto à implantação do Sistema de Avaliação da Educação Básica (SAEB) ${ }^{3}$, no Ensino Fundamental, o processo teve início em 1990, quando foi realizada a primeira aplicação de provas com levantamento de dados em todo o país, com assistência financeira e técnica de organismos internacionais, principalmente o Banco Mundial. O acordo com essa agência configurou-se como "pré-requisito para a obtenção de novos empréstimos, expressando a aproximação da educação com o setor produtivo na perspectiva do desenvolvimento e do crescimento econômico" (ZANARDINI, 2008, p. 167).

Com relação ao Ensino Médio, seguindo os mesmos princípios da política avaliativa, em 1998 foi implantado o Exame Nacional do Ensino Médio (ENEM), com o objetivo de avaliar o desempenho dos estudantes na conclusão da Educação Básica. Atualmente, além da classificação das escolas e dos sistemas de ensino, seus resultados constituem uma forma de acesso dos estudantes ao Ensino Superior, em instituições tanto públicas quanto privadas.

Embora o escopo de nossa discussão esteja situado no campo da EI, cabe observar que o início dessas reformas educacionais antecede sua integração ao nível da Educação Básica (BRASIL, 1996). Assim, ainda que a EI esteja inserida nesse contexto, salientamos que as avaliações externas ou em larga escala, embora presentes no escopo da Educação Básica, não são desenvolvidas na EI, que também integra esse nível de ensino como sua primeira etapa. De acordo com Zanardini (2008), a adoção de tais medidas avaliativas relaciona-se a políticas econômicas articuladas com organismos internacionais, como o Banco Mundial, visto que os resultados educacionais têm sido objeto de interesse também de cientistas políticos e econômicos. Deste modo, esses acontecimentos não ocorrem de forma isolada, sendo influenciados por um contex to mais amplo e integrando políticas vigentes no cenário mundial.

Sobre esse contexto, o autor destaca a relação existente entre a concepção de sociedade e a prática avaliativa, ao afirmar que

Há uma intencionalidade nos instrumentos avaliativos frente à ordem social a que se conformam. Dito de forma mais consistente há uma ontologia que os formata e que informa essa intencionalidade. Nas avaliações realizadas se reconhece a sociedade desejada, ou seja, na avaliação se conforma uma determinada visão de mundo. (ZANARDINI, 2008, p. 47).

Embora em um contexto fortemente marcado pela política de avaliação direcionada ao desempenho dos estudantes, na esteira das diferentes instâncias avaliativas, a publicação ${ }^{4}$, pelo MEC, de documentos com indicadores de qualidade para a Educação Básica enfatiza metodologias para o processo de avaliação institucional (BRASIL, 2011). Destacamos que essa ação avaliativa contribui para o fortalecimento e consolidação da gestão democrática, articulandose ao Projeto Político-Pedagógico da escola, aos princípios da qualidade na educação e aos sujeitos atuantes na prática educacional.

Retornando ao âmbito da legislação brasileira, no contexto atual, ao analisar o Plano Nacional de Educação (PNE), que aprova e estabelece diretrizes, metas e estratégias para a

\footnotetext{
${ }^{3}$ O SAEB é constituído de duas modalidades avaliativas: a Avaliação Nacional da Educação Básica (ANEB), exame de larga escala aplicado em uma amostra de escolas, e a Avaliação Nacional de Rendimento Escolar (ANRESC), exame de larga escala aplicado a todos os estudantes, introduzido em 2005 e conhecido como Prova Brasil (SOUSA; LOPES, 2010).

${ }^{4} \mathrm{O}$ trabalho contou com a participação de representantes de entidades governamentais e não governamentais, fóruns, conselhos, professores, gestores, especialistas e pesquisadores da área. A primeira publicação ocorreu em 2004, dirigiu-se ao Ensino Fundamental e ao Ensino Médio, com indicação de adequação para a EI. Em 2009 foram publicados os Indicadores da Qualidade na Educação Infantil e, em 2013, os Indicadores da Qualidade na Educação - Relações Raciais na Escola.
}

Práxis Educativa, Ponta Grossa, p. 812-831, v. 11, n. 3, set./dez. 2016 Disponível em: <http://www.revistas2.uepg.br/index.php/praxiseducativa> 
educação nacional nos próximos dez anos, Côco et al. (2015, p. 87) destacam que, "[...] entre as 20 metas do documento, nenhuma focaliza diretamente a avaliação. No entanto, a força da avaliação nas estratégias é muito grande, visto que 14 (70\%) metas apresentam no mínimo uma estratégia com previsão de ação avaliativa", ressaltando que, no conjunto das 255 estratégias, 26 $(10 \%)$ direcionam-se à ação avaliativa.

Estes dados indicam que o contexto das políticas educacionais, materializado no PNE, reconhece a avaliação como estratégia para que se atinjam as metas estabelecidas, o que se encontra em consonância com as influências de organismos internacionais. Assim, observamos que as avaliações externas ou de larga escala, embora não figurem entre as metas do PNE, longe de ocupar lugar secundário, mantêm a centralidade estratégica, incidindo sobre diferentes elementos constitutivos da educação, comoa formação, a gestão, a qualidade, a valorização docente, o currículo.

Nessa mesma conjuntura política e com foco na questão do currículo, assinalamos que

[...] há algo que é necessário discutir, tomando, por exemplo, as questões curriculares e formativas (mas não só) como preocupação pedagógica atual e como uma pauta importante da práxis educacional das ações afirmativas. [...] levando em conta o poder instituinte do currículo nos plurais cenários educacionais e sua história, envolvendo de forma significativa configurações de poder, esse dispositivo pedagógico tem assumido um lugar histórico educacional inigualável em termos contemporâneos. (MACEDO, 2012, p. 176, grifo do autor).

Ressaltando a importância do currículo, Brandalise (2007) afirma que ele se inter-relaciona com diferentes ações que permeiam a escola, visto que envolve todo o processo educativo, incluindo tanto as atividades planejadas quanto as desenvolvidas. A autora concebe o currículo como elemento central de referência para analisar o que a escola é, de fato, acentuando a relevância de sua perspectiva prática sobre a perspectiva teórica.

Articulando essa relevância da dimensão prática do currículo com os impactos das novas políticas, Marcondes e Moraes (2013) ressaltam as alterações na concepção do que é conhecimento, no que é ensinar e no que é avaliar, trazendo para a dinâmica do trabalho pedagógico, que envolve a avaliação e o currículo, duas lógicas irreconciliáveis, conforme podemos observar no quadro a seguir:

Quadro 1 - Síntese das lógicas de aprendizagem e de controle

\begin{tabular}{|c|c|c|}
\hline & Lógica de aprendizagem & Lógica do controle \\
\hline Conhecimento & $\begin{array}{l}\text { É visto como uma produção } \\
\text { cultural e parte da experiência } \\
\text { do aluno. }\end{array}$ & É visto como um conjunto de dados reificados. \\
\hline Ensinar & $\begin{array}{l}\text { É visto como um processo } \\
\text { coletivo com ênfase em tarefas } \\
\text { de grupo,em que os alunos } \\
\text { realizam trocas e ajudam-se } \\
\text { mutuamente. }\end{array}$ & $\begin{array}{l}\text { Significa transmitir noções e fatos com ênfase na } \\
\text { transmissão dos conteúdos pelo professor, em que } \\
\text { as tarefas são individuais, e prioriza-se a } \\
\text { memorização do conteúdo. }\end{array}$ \\
\hline Avaliação & É basicamente diagnóstica. & $\begin{array}{l}\text { Verifica a aquisição do conhecimento e é usada } \\
\text { para classificação de alunos e escolas. }\end{array}$ \\
\hline
\end{tabular}

Fonte: Elaborado pelas autoras a partir de Marcondes e Moraes (2013, p. 459).

Práxis Educativa, Ponta Grossa, p. 812-831, v. 11, n. 3, set./dez. 2016 Disponível em: <http://www.revistas2.uepg.br/index.php/praxiseducativa $>$ 
Sendo assim, não somente as diferentes instâncias avaliativas protagonizam esse campo de disputas, também o "[...] o currículo tem sido modificado com a introdução de novas abordagens - currículo baseado em competências - acompanhando as orientações de Agências Internacionais [...]" (BALL et al., 2013, p. 11). O autor ainda adverte que, não somente a definição do currículo, como a autonomia docente ficam subordinadas aos princípios ideológicos e aos dispositivos políticos que alimentam esse discurso.

As indagações sobre o currículo, presentes nas escolas e na teoria pedagógica, indicam a consciência de que os currículos não são conteúdos prontos a serem transmitidos aos alunos, mas práticas e conhecimentos que se inserem em diferentes dinâmicas, e são reinterpretados em cada contexto histórico (BRASIL, 2007b). Neste sentido, no documento produzido por solicitação do MEC intitulado Curriculo, Conbecimento e Cultura (BRASIL, 2007b, p. 18), Moreira e Candau assinalam que os debates sobre o currículo integram, de diferentes maneiras, "[...] discussões sobre os conhecimentos escolares, sobre os procedimentos e as relações sociais [...], sobre as transformações que desejamos efetuar nos alunos e alunas, sobre os valores que desejamos inculcar e sobre as identidades que pretendemos construir".

As autoras ainda realçam alguns princípios que devem perpassar as indagações, o estudo e a prática do currículo, tais como: necessidade de uma nova postura por parte do professorado e dos gestores; busca pela construção de currículos culturalmente orientados; reescritados conhecimentos escolares; evidenciada ancoragem social desses conhecimentos; e transformação da "[...] escola e o currículo em espaços de crítica cultural, de diálogo e de desenvolvimento de pesquisas" (BRASIL, 2007b). Integrando o mesmo documento, Fernandes e Freitas ressaltam a correlação do currículo com a avaliação, e destacam que a auto avaliação ainda não faz parte da cultura escolar brasileira. Entretanto, se quisermos sujeitos autônomos e críticos, devemos ter consciência de que tal prática deve compor o cotidiano dos planejamentos dos professores e do desenvolvimento do currículo (BRASIL, 2007b).

Todavia, o impacto das políticas econômicas, internacionais e nacionais, sobre os sistemas educativos, convoca a emergente discussão a respeito das influências da avaliação de larga escala no currículo da Educação Básica. Esse processo de discussão confirma a necessidade do outro como vital para nossa constituição como sujeitos (BAKHTIN, 2011), pressupondo, então, distintos posicionamentos, alianças, discordâncias e silenciamentos, o que implica aproximações, tensões e contradições.

Nesses tensionamentos, o contexto da produção de textos, que se materializa em documentos oficiais e representa a política (BALL, 2001; MAINARDES; MARCONDES, 2009), evidencia disputas e conquistas na Educação Básica e ajuda a compreender o cenário atual. Assim, possibilita ampliar perspectivas de análise quanto às tendências relacionadas à avaliação e ao currículo, que se configuram no campo da EI em sua recente composição como etapa inicial no contexto da Educação Básica.

\section{A especificidade da Educação Infantil como primeira etapa da Educação Básica}

Em um movimento retrospectivo da recente trajetória da EI como integrante da Educação Básica visualizamos, por meio de diversas mudanças na legislação e na política educacional, a tendência de reconhecimento deste nível de ensino em seu processo de consolidação como parte do sistema educacional brasileiro, e em seus desafios na expansão do

Práxis Educativa, Ponta Grossa, p. 812-831, v. 11, n. 3, set./dez. 2016 Disponível em: <http://www.revistas2.uepg.br/index.php/praxiseducativa > 
atendimento às crianças de 0 a 5 anos ${ }^{5}$.

Reiterando alguns marcos desse percurso destacamos, em um processo de conquistas legais, a Constituição Federal (BRASIL, 1988) e o Estatuto da Criança e do Adolescente (BRASIL, 1990). Em ambos os documentos, a EI é considerada como dever do Estado e como direito das crianças, não mais como um serviço oferecido pela assistência social às populações pobres, o que se configura em importante conquista social e política, contrastando com premissas expressas em documentos do Banco Mundial, que focalizam a competitividade, a eficácia e a formação de mão de obra.

Após essas determinações legais, passaram quase dez anos até que a LDB (BRASIL, 1996) regulamentasse a EI como primeira etapa da Educação Básica, estabelecendo sua oferta como responsabilidade dos municípios em regime de colaboração com os estados e a União. Conforme assinala Cury (2002), a mudança na legislação nacional (BRASIL, 1996) representa a luta de educadores para a formalização de alguns objetivos almejados, possibilitando um olhar diferenciado para a educação. Desse modo, "a ideia de desenvolvimento do educando nestas etapas que formam um conjunto orgânico e sequencial é a do reconhecimento da importância da educação escolar para os diferentes momentos destas fases da vida" (CURY, 2002, p. 170).

Entretanto, mesmo concordando com essa perspectiva de organicidade e de conjunto da educação na legislação, problematizamos com Oliveira (2013) que a inclusão da EI, como etapa inicial da Educação Básica, representa desafios, visto que

Tal medida obriga a que se pense o profissional da educação básica em um contexto e rol mais complexo de atividades, responsabilidades e competências que envolvem desde o cuidado e a atenção no processo educativo presentes na educação infantil até a fragmentação disciplinar própria do ensino médio. O contraste entre essas duas pontas da educação básica é tão grande que dificulta pensar a possibilidade de um grupo homogêneo que possa constituir-se em um corpo profissional. (OLIVEIRA, 2013, p. 63).

Articulando esses desafios à dimensão do financiamento, cabe demarcar que,somente 11 anos após a promulgação da LDB (BRASIL, 1996), a EI passou a receber recursos do Fundo de Manutenção e Desenvolvimento da Educação Básica e de Valorização dos Profissionais da Educação (FUNDEB) (BRASIL, 2007a).Salientamos que essa inclusão da EI no FUNDEB não se deu sem lutas;ao contrário, foi a partir de grande mobilização social ${ }^{6}$ que a EI garantiu sua inserção (BRASIL, 2007a), alcançando importante conquista sob o aspecto do financiamento educacional, no que diz respeito à ampliação do atendimento e à valorização do trabalho docente.

Reconhecemos que a aprovação dessas e de outras bases legais reflete o contexto de reivindicações que marca o cenário da EI. Reivindicações que se compõem mediante as diferentes dinâmicas sociais e que, em um movimento circundante, vão imprimindo outras mudanças na sociedade. No entanto, como a EI encontra-se em processo de constituição, a legislação unicamente não viabiliza avanço nas demandas que se apresentam, mas concordamos que as prescrições legais juntam-se às lutas que permanecem nessa etapa.

\footnotetext{
${ }^{5}$ Desde a promulgação da LDB n. ${ }^{\circ}$ 9394/1996, o termo Educação Infantil é utilizado para se referir às instituições educativas destinadas às crianças de 0 a 6 anos. No entanto, com a aprovação da Lei n. ${ }^{\circ} 11.114$, de 2005, que tornou obrigatório o início do Ensino Fundamental aos 6 anos de idade, a EI passou a atender à faixa etária de 0 a 5 anos, embora, em razão de data de corte etário, também sejam atendidas crianças de 6 anos.

${ }^{6}$ Por intermédio do movimento FUNDEB pra valer, diversas ações de mobilização ocorreram de março de 2004 a maio de 2007, coordenadas pela Campanha Nacional pelo Direito à Educação, com a participação de outros movimentos e organizações sociais, entre os quais o Movimento Interfóruns de Educação Infantil do Brasil (MIEIB).
}

Práxis Educativa, Ponta Grossa, p. 812-831, v. 11, n. 3, set./dez. 2016 Disponível em: < http://www.revistas2.uepg.br/index.php/praxiseducativa > 
No que se refere à oferta de vagas, embora tenha sido verificado um crescimento no atendimento às crianças na EI, ele ainda é insuficiente para a demanda existente.Segundo o Censo Populacional 2010, realizado pelo IBGE com periodicidade decenal, das 16.728 .146 crianças brasileiras com idade entre 0 e 5 anos, as matrículas na EI totalizam 6.756.698, ou seja, menos de 50\% das crianças atendidas, o que representa um grande desafio (IBGE, 2010).

Em direção à ampliação da oferta de vagas, o PNE de 2001-2010 já estabelecia o atendimento de $50 \%$ das crianças de 0 a 3 anos até 2005, mas esta meta não foi atingida, e agora permanece como desafio para o final da vigência do PNE atual. Isto mantém as tensões que envolvem a expansão da oferta de vagas na EI.

Sendo assim, esse percurso de constituição da legislação referente à EI relaciona-se diretamente com os dados de atendimento atual, evidenciando que o atendimento ${ }^{7}$ da EI no país é realizado, em sua maior parte, pelos municípios, que são responsáveis por mais de $72,4 \%$ da oferta das matrículas em creches e pré-escolas. Embora a responsabilidade legal pela oferta de vagas nessa etapa seja dos municípios, ela precisa acontecer em articulação com os demais entes federados. Conforme previsto no art. 7. ${ }^{\circ}$ do Plano Nacional de Educação (PNE), “[...] a União, os Estados, o Distrito Federal e os Municípios atuarão em regime de colaboração, visando ao alcance das metas e à implementação das estratégias objeto deste Plano" (BRASIL, 2014b, p. 1).

Com base em concepções afirmadas em documentos oficiais já publicados, entendemos que ações avaliativas podem integrar as dinâmicas da EI, em consonância com sua especificidade. Nessa perspectiva, as concepções constantes no documento Educação Infantil: Subsídios para Construção de uma Sistemática de Avaliação (BRASIL, 2012) afirmam que a prática de avaliação institucional e a construção de um referencial de qualidade para a instituição de EI precisam efetivar-se com os profissionais, as famílias e as crianças.

Portanto, é preciso considerar as diferentes vozes, os ilimitados sentidos, os enunciados que integram a avaliação institucional como um processo dialógico (BAKHTIN, 2011), complementando a ideia da participação de todos os envolvidos, o que pressupõe discordâncias, divergências, consensos, parcerias, conflitos, enfim, infinitas possibilidades interativas. Neste sentido, cabe realçar que o processo avaliativo,em uma perspectiva participativa, requer mais que instrumentos ou escalas para se efetivar. Ao analisar as concepções e vivências relacionadas ao processo de gestão democrática que devem embasar a avaliação institucional, Sousa (2006, p. 138) enfatiza que

[...] a avaliação institucional abrange a análise da instituição educativa como um todo, nas dimensões política, pedagógica e administrativa, tem como marco o projeto pedagógico e visa subsidiar seu contínuo aprimoramento, por meio do julgamento das decisões tomadas pelo coletivo da instituição, das propostas delineadas e das ações que foram conduzidas, suas condições de realização e os resultados que vêm sendo obtidos.

Tendo como princípio que nos constituímos em contexto situado histórica e socialmente, Bakhtin inspira a compreender os eventos não de forma isolada, mas conectados simultaneamente ao passado, ao presente e ao futuro, com ecos e ressonâncias entre essas temporalidades. Nesta perspectiva de encadeamento, enquanto estudiosos, pesquisadores e militantes fomentavam pesquisas, estudos, debates, eventos e articulações acerca dos documentos que buscavam, em meio aos dissensos, fortalecer concepções sobre o campo da EI. A Secretaria de Ações Estratégicas do Governo Federal decidiu realizar, em 2010-2011, por meio da Secretaria Municipal de Educação do Rio de Janeiro, a aplicação de um questionário com o objetivo de

\footnotetext{
${ }^{7}$ Derivado de sinopse estatística da Educação Básica de 2014. Disponível em: <http://portal.inep.gov.br/basicacenso-escolar-sinopse-sinopse>. Acesso em: 13 jun. 2015.
}

Práxis Educativa, Ponta Grossa, p. 812-831, v. 11, n. 3, set./dez. 2016 Disponível em: <http://www.revistas2.uepg.br/index.php/praxiseducativa> 
avaliar as crianças da EI. Esse questionário caracteriza-se como um modelo padronizado de avaliação das crianças, com base em um instrumento estadunidense, o Age and Stages Questionnaires (ASQ-3) ${ }^{8}$, a fim de estabelecer os níveis de desenvolvimento das crianças em todo o país.

Essa iniciativa provocou muitos protestos no âmbito das organizações sociais e de pesquisa. Assumindo posicionamento contrário a esse processo, Neves e Moro (2013, p. 275) afirmam que "[...] os princípios teóricos desse instrumento são sustentados por uma clara concepção inatista e biológica do desenvolvimento humano, com grande ênfase na maturação neurológica das crianças". Integrando posicionamentos de indignação e repúdio, o Movimento Interfóruns de Educação Infantil do Brasil (MIEIB), o Fórum Paulista de Educação Infantil (FPEI) e a ANPEd manifestaram preocupação e oposição de diversas formas, mobilizando educadores e militantes nas redes sociais, em debates e em audiências públicas.

As bases de argumentação dessa oposição ao ASQ3 sustentaram-se na própria trajetória da EI, destacando que esse instrumento e outros procedimentos similares desconsideram as concepções de EI e de avaliação presentes em documentos mandatórios (BRASIL, 1996, 2009a) e orientadores (BRASIL, 2009b) discutidos coletivamente (ANPEd, GT 07 - Educação de crianças de 0 a 6 anos, 2012) ${ }^{9}$. Além disso, concordamos que esses fundamentos, já conquistados legalmente, precisam configurar-se como avanços que possibilitem a efetivação de práticas avaliativas em consonância com as concepções teóricas e, sobretudo, com as diferentes vozes, culturas e vivências das crianças (FÓRUM PAULISTA DE EDUCAÇÃO INFANTIL, 2012) ${ }^{10}$.

Nessa mesma direção, defendemos que a conquista do reconhecimento da EI, como primeira etapa da Educação Básica, precisa dialogar com a afirmação de sua especificidade e, fundamentados nessa premissa, advogamos que "[...] as crianças brasileiras não precisam de modelos externos para a avaliação de seu desenvolvimento nem para a validação das práticas cotidianas que com elas são desenvolvidas” (MIEIB, 2011, p. 3) ${ }^{11}$.

Formalizando a análise sobre a aquisição de direitos autorais do instrumento de avaliação americano pelo MEC, a Coordenação Geral de Educação Infantil (COEDI) apresentou as seguintes razões para sua recusa:

O ministério está criando GT para formulação da política de avaliação da e na Educação Infantil; a definição da política precede a escolha de metodologia e instrumentos; o ASQ-3 não apresenta coerência com a concepção de criança expressa nas Diretrizes Curriculares Nacionais para a Educação Infantil - DCNEI e não se caracteriza como uma metodologia de avaliação da política de Educação Infantil (BRASIL, 2012, p. 10).

Nesse quadro de movimentados debates, a luta segue no intuito de "demarcar uma sistemática que enfatiza a avaliação das condições da oferta de creches/pré-escolas numa perspectiva de avaliação democrática, que respeita e protege direitos das crianças em contextos de desigualdade e diversidade" (VIEIRA, 2014, p. 33). Assim, compondo a Educação Básica e mantendo especificidades próprias de seu percurso de transformações, desde sua origem na

\footnotetext{
${ }^{8} \mathrm{O}$ detalhamento desse instrumento pode ser consultado no Manual de Uso do ASQ-3 - guia rápido para aplicação do ASQ-3, divulgado pela Prefeitura Municipal do Rio de Janeiro. Disponível em: <http://200.141.78.79/dlstatic/10112/1132535/DLFE-205901.pdf/1.0>. Acesso em: 11 ago. 2012.

${ }_{9}$ Disponível em: <http://www.observatoriodaeducacao.org.br/index.php/sugestoes-de-pautas>. Acesso em: 27 mar. 2014.

${ }^{10}$ Disponível em: <http://www.mieib.org.br/pagina.p?menublogs\&codigo=7\&area=biblioteca\&id9>. Acesso em: 15 fev. 2015.

${ }^{11}$ Disponível em: <http://www.observatoriodaeducacao.org.br/images/pdfs/manisfestomieib.pdf.>. Acesso em: 15 fev. 2015.
}

Práxis Educativa, Ponta Grossa, p. 812-831, v. 11, n. 3, set./dez. 2016 Disponível em: <http://www.revistas2.uepg.br/index.php/praxiseducativa $>$ 
Assistência Social (KUHLMANN JR, 2000), as questões que envolvem a avaliação institucional e o currículo na EI carregam peculiaridades que constituem sua trajetória. Essas singularidades anunciam perspectivas e encontram-se expressas em grande parte dos documentos mandatórios e orientadores, elaborados ao longo das últimas décadas, na busca de propostas de trabalho que dialoguem com a especificidade do atendimento às crianças pequenas e sejam construídos em uma perspectiva coletiva e participativa.

\section{Avaliação institucional e currículo na Educação Infantil: proposições e perspectivas}

No conjunto de desafios que circundam o campo da EI, consideramos que a interlocução entre a avaliação institucional e o currículo constitui um dos mais recentes, uma vez que as duas temáticas estão pautadas na agenda da primeira etapa da Educação Básica.

As discussões e a sistematização da Base Nacional Comum Curricular ${ }^{12}$ estão em pleno desenvolvimento, envolvendo professores, movimentos sociais e sindicais, familiares, pesquisadores, enfim, todos que têm interesse na temática. São diversas universidades e vários pesquisadores envolvidos nas equipes de trabalho, desde 2010. Atualmente, com a publicação da proposta preliminar ${ }^{13}$, iniciou uma nova etapa na elaboração da BNCC, que é o debate público com participação mediante plataforma online para registro das proposições de todos os interessados no assunto.

Em relação à avaliação institucional ou avaliação de contexto, o campo da EI encontra-se na expectativa da aprovação da Avaliação Nacional da Educação Infantil (ANEI) pelo Ministério da Educação e, por conseguinte, da viabilidade de condições (equipe e recursos) para sua realização pelo INEP. Ao longo de dois anos, a proposta da ANEI foi elaborada em uma ação do Núcleo de Estudos e Pesquisas em Infância e Educação Infantil da Universidade Federal do Paraná com outras três universidades brasileiras (Universidade Federal de Minas Gerais, Universidade Federal do Rio de Janeiro e Universidade do Estado de Santa Catarina). Contou, ainda, com a universidade italiana - Università degli studi di Pavia/Itália - e com a parceria técnica e financeira da Secretaria de Educação Básica do Ministério da Educação ${ }^{14}$.

Uma questão que merece ser considerada, quando se pensa em discutir o currículo na EI, articula-se intrinsecamente à sua vinculação com a avaliação da aprendizagem. Mesmo reconhecendo a importância dessa relação, evidenciamos, neste texto, a avaliação institucional como uma prática dinâmica que possibilita aos sujeitos, como falantes (BAKHTIN, 2011), expressar suas ideias, compreensões, dúvidas, enfim, vivenciar movimentos democráticos de participação que põem em análise, entre outros aspectos, a proposta curricular da instituição.

Por isso, a possibilidade de interlocução entre esses dois importantes elementos que integram o campo da EI encontra-se aberta a reflexões, análises, debates e proposições. Para fomentar esse diálogo entre a avaliação institucional e o currículo na EI, abordamos aspectos da legislação em articulação com estudos e pesquisas desenvolvidas sobre as temáticas em questão.

\footnotetext{
${ }^{12}$ A consulta pública permaneceu aberta a todos os interessados em enviar suas contribuições até 15 de março de 2015, através do endereço eletrônico: < http://basenacionalcomum.mec.gov.br/\#/site/contribua-inicio>. Disponível até 15 de março de 2015.

${ }^{13}$ Disponível em: <http://basenacionalcomum.mec.gov.br/\#/site/contribua-inicio>. Acesso em: 24 out. 2015.

${ }^{14}$ Disponível em: <http://www.anped.org.br/news/anei-e-educacao-infantil-entrevista-com-gizele-de-souza-gt-07> Acesso em: 15 out. 2015.
}

Práxis Educativa, Ponta Grossa, p. 812-831, v. 11, n. 3, set./dez. 2016 Disponível em: <http://www.revistas2.uepg.br/index.php/praxiseducativa> 
Focalizando inicialmente as questões curriculares, acreditamos que, para organizar o currículo da EI, é preciso considerar conteúdos, saberes, conhecimentos e experiências, assumindo o currículo como um dos princípios do projeto pedagógico da instituição e problematizando-o,em um processo democrático de discussão.

Destacando uma importante marca desse processo democrático, assinalamos a publicação do documento Referencial Curricular Nacional para a Educação Infantil - RCNEI (BRASIL, 1998). Este material, apresentado em três volumes, configurou-se como documento contendo recomendações para as práticas pedagógicas na EI. No contexto de elaboração do RCNEI, a ação pública dos integrantes do GT7 da ANPEd promoveu intensos debates teóricos e políticos, tendo por bases "[...] a autonomia do campo cultural e o relacionamento dos intelectuais com o mundo social" (MOLETTA; CAMPOS, 2015, p. 553). Desse modo, esses agentes "[...] intervieram no cenário público para manifestar suas posições de crítica ao documento emanado da COEDI/MEC que objetivava estabelecer diretrizes nacionais à EI" (MOLETTA; CAMPOS, 2015, p. 545).

Em seguida, o Conselho Nacional de Educação instituiu as Diretrizes Curriculares Nacionais para a Educação Infantil -DCNEI - (BRASIL, 1999). Com força de lei, as diretrizes elaboradas naquele momento consolidaram a discussão em torno da importância da qualidade da EI para a garantia dos direitos das crianças.

Em meio a diversos movimentos e elaboração de documentos circundantes à questão curricular, direcionamo-nos ao que está estabelecido no art. $3 .^{\circ}$ das atuais DCNEI:

O currículo da Educação Infantil é concebido como um conjunto de práticas que buscam articular as experiências e os saberes das crianças com os conhecimentos que fazem parte do patrimônio cultural, artístico, ambiental, científico e tecnológico, de modo a promover o desenvolvimento integral das crianças. (BRASIL, 2009a).

Assim, a proposta pedagógica das instituições de EI tem maior possibilidade de, em convergência com o art. 7. das DCNEI (BRASIL, 2009a), garantir que elas cumpram plenamente sua função sociopolítica e pedagógica.

Tomando como ponto de partida um estudo de Barbosa (2010) sobre currículo na EI, assinalamos que a ampliação das concepções de conhecimento e aprendizagem para além da racionalidade ocidental constitui-se como

[...] um radical desafio, pois exige compreender o currículo não apenas como um plano
prévio de ensinar a vida, mas também como abertura à experiência de viver, junto com os
bebês e as crianças pequenas, as situações propostas. A dificuldade está em mudar
nossa concepção de currículo como "fabricação" do humano para currículo como
narração do humano, que diz respeito ao agir. Empreender essa mudança implica
priorizar a atitude de respeito à condição humana de buscar sentidos para o viver junto.
(BARBOSA, 2010, p. 8, grifos nossos).

Ao analisar os resultados da avaliação de propostas curriculares para a EI de municípios brasileiros, buscando compreender o que os sujeitos enunciavam sobre as finalidades dessas propostas, a autora assinala, entre outros pontos, a importância do processo de construção participativa da proposta curricular. Tal processo possibilitou, ao município, conhecer as demandas da comunidade e, ao mesmo tempo, realizar a formação dos docentes no desenvolvimento do processo. Ademais, a autora afirma que a concepção de processo pedagógico só existirá se houver intencionalidade, a qual exige que a instituição tenha uma proposta curricular explícita. 
Considerando a relevância das propostas curriculares, há que garantir, também, a continuidade dos processos de aprendizagem das crianças nos diferentes momentos de transição vividos, tanto em seu ingresso na instituição de EI, junto aos familiares, quanto em suas mudanças de turmas no interior da instituição, e sua transição da creche e a da pré-escola, e para o Ensino Fundamental (OLIVEIRA, 2010). A autora ressalta a necessidade de fortalecimento dos processos de formação continuada para qualificar as práticas pedagógicas existentes, atentando para o fato de que

\begin{abstract}
Muitas instituições encontram-se presas a modelos que já foram avaliados e julgados inadequados como instrumentos de educar e cuidar e promover o desenvolvimento das crianças. Em parte a presença desses modelos é devida à longa tradição assistencialista presente no processo de constituição da área de Educação Infantil, em particular em relação à creche, o que prejudicou a elaboração modelos pedagógicos mais afinados com as formas de promoção do desenvolvimento infantil. (OLIVEIRA, 2010, p. 14).
\end{abstract}

Sobre essa questão, Haddad (2012) enfatiza que uma das grandes questões discutidas sobre o currículo para a EI é se ele deve apresentar orientações mais diretivas, ou se organizar em diretrizes mais gerais. Ponderando as duas possibilidades e articulando cada uma à questão da formação docente, a autora adverte que as duas propostas apresentam ressalvas. Essa análise impele a ressaltar a importância dos debates e estudos que considerem as questões curriculares e avaliativas na interlocução com a formação inicial e continuada.

De acordo com a consulta ${ }^{15}$ feita pelo MEC por intermédio do Sistema Integrado de Monitoramento Execução e Controle (SIMEC), sobre a elaboração de orientações curriculares a partir da publicação das Diretrizes Curriculares Nacionais para a Educação Infantil -DCNEI (BRASIL, 2009a), considerando as respostas de 2.554 municípios, a situação apresenta-se da seguinte forma: $47,30 \%$ dos respondentes afirmaram que, em seu município, há orientações curriculares elaboradas; $24,71 \%$ declararam não ter proposta curricular; 25,22\% informaram que as orientações curriculares estão em elaboração e 2,78\% afirmaram não ter informações sobre o assunto (MEC, 2015).

Esses dados, produzidos seis anos depois da publicação das DCNEI, evidenciam um dos desafios da EI, no que se refere à questão do currículo. Ao agruparmos os quantitativos de respostas que indicaram não ter as orientações curriculares elaboradas, com os que informaram que as orientações curriculares estão em elaboração, temos um percentual de 49,93\%, perfazendo um total maior de municípios ainda sem a elaboração de orientações curriculares.

Em abordagem ampliada, a questão curricular já se apresenta, na legislação brasileira, desde a Constituição Federal (BRASIL, 1988), em seu art. 210, na LDB (BRASIL, 1996), no art. 26, e no art. 14 da Diretriz Curricular Nacional para a Educação Básica - DCNEB (BRASIL, 2010). Porém, embora estes apontamentos legais se refiram Educação Básica, nem sempre contemplaram a EI. Com nova redação dada pela Lei n. ${ }^{\circ} 12.796 / 13$, o art. 26 da LDB, que trata de currículo, incluiu a EI junto às duas outras etapas da Educação Básica. No eixo IV da Conferência Nacional de Educação (CONAE) (BRASIL, 2014a), todos os níveis, etapas e modalidades são contemplados na estratégia que prevê a garantia de acesso e permanência com qualidade à aprendizagem na educação. Entretanto, a estratégia de elaboração de consulta pública nacional, sobre a proposta de direitos e objetivos de aprendizagem e desenvolvimento, direcionase apenas aos alunos do Ensino Fundamental e Médio.

Quanto à estratégia 7.1 (BRASIL, 2014b), embora explicite que as diretrizes pedagógicas a serem estabelecidas são para a Educação Básica, declara que os direitos e objetivos de

${ }^{15}$ Disponível em: <http://portal.mec.gov.br/buscaword=Consulta\%20P\%C3\%BAblica>. Acesso em: 23 out. 2015.

Práxis Educativa, Ponta Grossa, p. 812-831, v. 11, n. 3, set./dez. 2016 Disponível em: <http://www.revistas2.uepg.br/index.php/praxiseducativa > 
aprendizagem e desenvolvimento estão voltados ao Ensino Fundamental e Médio.Em relação à meta 1, destacamos a estratégia 1.9, que articula a discussão e elaboração dos currículos com os avanços de estudos e pesquisas desenvolvidos em programas de pós-graduação e por grupos de pesquisa sobre o processo de ensino-aprendizagem das crianças de 0 a 5 anos (BRASIL, 2014b).

A respeito da abordagem sobre a gestão democrática, realçamos a importância da meta 19.6 (BRASIL, 2014b, p. 7, grifo nosso), que se direciona a "estimular a participação e a consulta de profissionais da educação, alunos (as) e seus familiares na formulação dos projetos políticopedagógicos, currículos escolares, planos de gestão escolar e regimentos escolares [...]", e assegura a participação dos pais no processo avaliativo, embora focalize apenas a avaliação dos professores e do gestor. No conjunto das estratégias do PNE, esta é a única em que currículo e avaliação figuram associados no texto da lei, sem que possamos, contudo, afirmar sua interlocução, uma vez que o foco é a gestão democrática.

No encadeamento das discussões, focalizamos, nesta parte do texto, questões atinentes à avaliação institucional na EI, compreendendo esse processo em perspectiva participativa e de construção coletiva com os docentes, crianças e seus familiares.

Quando aborda a questão da avaliação na EI, Rosemberg (2013) assinala que o termo/tema avaliação vem adentrando o campo da etapa inicial da Educação Básica, configurando um novo problema social.Isto não significa que as discussões sobre a avaliação deixaram de existir no campo da primeira etapa da Educação Básica, mas lhe confere maior visibilidade, promovendo tensões e assumindo um lugar nas políticas públicas. Como já destacamos, a EI é a única etapa que não se insere no quadro de políticas avaliativas em larga escala com testes padronizados direcionados às crianças, como ocorre nos ensinos Fundamental e Médio.

Ainda de acordo com a autora, só muito recentemente, no Brasil, vem sendo formalizada uma política de avaliação, mesmo sem clareza do foco: se da ou na EI. A autora argumenta que, ao assumir o status de problema social, a avaliação na/da EI passa a exigir a atenção pública como um assunto de política social. Desse modo, o tema "[...] passa a ser delimitado, enquadrado como problema, entra na agenda e na pauta de negociações de políticas sociais, busca visibilidade e legitimidade públicas, recursos e incita defensores/apoiadores (stakeholders), bem como opositores" (ROSEMBERG, 2013, p. 47).

Reconhecemos que, conforme previsto legalmente, cabe ao Estado garantir os direitos das crianças à EI, incluindo, além de condições de acesso e oferta, padrões mínimos de qualidade. É importante ressaltar que o acompanhamento desse atendimento com qualidade deve ocorrer por meio de processos avaliativos, contudo, sem incluir uma avaliação endereçada ao desenvolvimento e aprendizagem das crianças para esta finalidade.

No contexto do PNE, em relação à avaliação direcionada especificamente à EI, analisamos a meta 1, que prevê a universalização, até 2016, do atendimento escolar às crianças de 4 e 5 anos, e a ampliação,durante a vigência do PNE, da oferta de EI a 50\% das crianças de até 3 anos. $\mathrm{Na}$ estratégia 1.6, relativa a essa meta, encontramos a previsão de

[...] implantar, até o segundo ano da vigência deste PNE, avaliação da educação infantil, a ser realizada a cada dois anos, com base em parâmetros nacionais de qualidade, a fim de aferir a infraestrutura física, o quadro de pessoal, as condições de gestão, os recursos pedagógicos, a situação de acessibilidade, entre outros indicadores relevantes. (BRASIL, 2010, grifos nossos).

Práxis Educativa, Ponta Grossa, p. 812-831, v. 11, n. 3, set./dez. 2016 Disponível em: <http://www.revistas2.uepg.br/index.php/praxiseducativa $>$ 
Essa definição reafirma a importância de aprofundar estudos acerca da temática da avaliação na EI. Essa aferição exige opções acerca da sistemática de avaliação a ser adotada, e os princípios dessa opção direcionam quem define os outros indicadores relevantes, de forma que estes

[...] não incidam sobre as crianças, que elas não sejam avaliadas como forma de aferir a qualidade da EI, demarcando que a avaliação da EI seja baseada em indicadores que focalizem as condições do que lhes é oferecido no seu processo de desenvolvimento, de aprendizagem e de apropriação do conhecimento. (CÔCO et al., 2015, p. 88).

Bondioli (2013) complementa essa abordagem e ressalta, no contexto da EI, a importância da avaliação institucional em perspectiva participativa, ao afirmar que,

[...] metodologicamente esse tipo de avaliação envolve, em posições de paridade, diversos grupos de interesse e diversas perspectivas, usando debate e o conflito entre posições diversas de maneira construtiva, através de formas de negociação. O escopo da avaliação não é chegar a uma 'verdade' objetiva, mas a uma construção de sentido (meaning making) que espelhe e conecte o máximo possível as percepções das partes atuantes ou explicite suas divergências. (BONDIOLI, 2013, p. 37, grifos da autora).

No intuito de conhecer o posicionamento dos docentes, em articulação com a pesquisa Trabalho Docente na Educação Básica no Brasil (OLIVEIRA; VIEIRA, 2010), Côco (2012) aborda a atuação docente na EI e focaliza o cenário do Espírito Santo, indicando que há, por parte dos docentes, "uma abertura para submissão à avaliação da comunidade educativa (89.9\% de aceitação), tendo variadas perspectivas de interlocutores" (CÔCO, 2012, p. 72).

Assim, percebemos que a ideia de vivenciar um processo avaliativo com diferentes interlocutores tem aceitação dos docentes. Contudo, na EI, essas experiências são ainda reduzidas. Considerando a realidade do Espírito Santo, com base nos dados do Mapeamento da Educaşão Infantil no contexto do Espirito Santo (PESQMAP), Côco e Vieira (2014, p. 43) informam que, especificamente em relação à avaliação institucional, "36 municípios capixabas (44\%) declararam que não há o desenvolvimento dessa modalidade avaliativa nas instituições de EI. Para 23 municípios, que representam 32\%, a avaliação institucional já é uma realidade".

Esses dados contextualizam a temática, indicando que essa prática avaliativa ainda não se integra à dinâmica de muitas de nossas instituições públicas de EI, o que demonstra que a sistematização da avaliação institucional requer outras abordagens formativas e informativas para que seja vivenciada como parte do cotidiano das instituições de EI. Cabe salientar que a avaliação institucional efetiva-se com a participação dos sujeitos que constituem as instituições de EI, atribuindo sentidos a todas as ações institucionais. E isso requer que cada um se sinta partícipe, integrante desse conjunto.

Portanto, a produção de textos relativos às políticas públicas relacionadas à avaliação institucional e ao currículo na EI evidencia que há uma sustentação no que tange a documentos mandatórios e orientadores, possibilitando embasamento do trabalho nesse campo.Assim, permite caminhar no sentido de consolidar a EI nesse contexto, promovendo interlocução entre as práticas avaliativas e de currículo em perspectiva dialógica, de interlocução, e não somente de hierarquização.

\section{Considerações finais: questões que permanecem}

Neste texto abordamos a questão da avaliação institucional e do currículo na EI no cenário das políticas educacionais brasileiras, considerando os contextos de produção de texto, conforme a abordagem do ciclo de políticas de Stephen Ball. As questões relativas à avaliação

Práxis Educativa, Ponta Grossa, p. 812-831, v. 11, n. 3, set./dez. 2016 Disponível em: <http://www.revistas2.uepg.br/index.php/praxiseducativa > 
institucional e ao currículo não se situam apenas no campo da EI, compondo um conjunto articulado às outras etapas da Educação Básica, em meio aos contextos diferenciados das políticas públicas em nosso país. Nesse cenário, a EI integra um panorama ampliado, em que se destacam conquistas e apresentam-se desafios característicos do contexto vivido.

$\mathrm{Na}$ interlocução com estudos de pesquisadores brasileiros e estrangeiros, documentos do Banco Mundial e documentos orientadores e mandatórios referentes à legislação brasileira, evidenciamos que a EI dispõe de sustentação teórica e legal no que tange à avaliação e ao currículo. Assim, fortalece o percurso de consolidação de seu pertencimento à Educação Básica em simultaneidade à demarcação de sua especificidade.

Nesse encontro dialógico com as produções analisadas, ressaltamos que a potencialidade de cada ator social em ressignificar/recriar, e até mesmo inaugurar práticas inovadoras relacionadas às políticas em suas várias abrangências, precisa ser movimentada em direção a desenvolver práticas avaliativas e curriculares que fortaleçam processos participativos que considerem as crianças como sujeitos de direito, capazes de produzir cultura.

Considerando os ordenamentos legais e as publicações elaboradas ao longo dos últimos 20 anos, o campo da EI vem, em perspectiva coletiva junto a pesquisadores e movimentos sociais, consolidando concepções e definindo princípios que contribuem para sua constituição diante das questões curriculares (Base Nacional Comum Curricular - BNCC) e da sistemática de avaliação institucional ou de contexto (Avaliação Nacional da Educação Infantil - ANEI).

Destacamos que essa elaboração articula-se com contextos mais amplos das políticas sociais nacionais e internacionais e problematizamos que, se, por um lado, as publicações caracterizam um alinhamento com essas políticas, por outro materializam resistências assumidas durante as últimas décadas por movimentos sociais, docentes, pesquisadores, associações e entidades engajadas com a EI. Na defesa da qualidade como direito das crianças, a legislação referente à EI contribui para o fortalecimento de concepções que balizam os debates no campo, e sustentam posicionamentos no sentido de valorizar a participação dos sujeitos envolvidos em questões curriculares e avaliativas.

\section{Referências}

AFONSO, A. J. Mudanças no Estado-avaliador: comparativismo internacional e teoria da modernização revisitada. Revista Brasileira de Educação, Rio de Janeiro, v. 18, n. 53, p. 267 284, abr./jun. 2013. DOI: 10.1590/s1413-24782013000200002

ASSOCIAÇÃO NACIONAL DE PÓS-GRADUAÇÃO E PESQUISA EM EDUCAÇÃO ANPED. ANEI e Educação Infantil - Entrevista com Gizele de Souza (GT 07). < http://www.anped.org.br/news/anei-e-educacao-infantil-entrevista-com-gizele-de-souza-gt-07>. Acesso em: 23 out. 2015.

BAKHTIN, M. M. Estética da criação verbal. Tradução de Paulo Bezerra. 6. ed. São Paulo: Martins Fontes, 2011.

BALL, S. J.;BAILEY, P.; MENA, P.; DEL MONTE, P.; SANTORI, D.; TSENG, C.; YOUNG, H.; OLMEDO, A.A constituição da subjetividade docente no Brasil: um contexto global. Educação em Questão, Natal, v. 46, n. 32, p. 9-36, maio/ago. 2013. 
BALL, S. J. Diretrizes políticas globais e relações políticas locais em educação. Currículo sem Fronteiras, v. 1, n. 2, p. 99-116, 2001.

BALL, S. J. Performatividade, privatização e o pós-estado do bem-estar. Educação \& Sociedade, Campinas, v. 25, n. 89, p. 1105-1126, set. 2004. DOI: 10.1590/s010173302004000400002

BANCO MUNDIAL. Relatório Anual de 2013 do Banco Mundial Washington, DC: Banco Mundial. DOI: 10.1596/978-0-8213-9942-2. Licença: Creative Commons Atribuição Sem Derivações - Sem Derivados CC BY 3.0. Disponível em: <https://openknowledge.worldbank.org/bitstream/handle/10986/16091/9780821399422PT.pd f.sequence $=5>$. Acesso em: 14 jun. 2015.

BANCO MUNDIAL. Relatório Anual de 2014 do Banco Mundial Washington, DC: Banco Mundial. DOI: 10.1596/978-1-4648-0245-4. Licença: Creative Commons Atribuição Sem Derivações - Sem Derivados 3.0 OIG (CC BY-NC-ND 3.0 IGO). Disponível em: http://www.worldbank.org/pt/country/brazil>. Acesso em: 14 jun. 2015.

BARBOSA, M. C. S. Os resultados da avaliação de propostas curriculares para a Educação Infantil dos municípios brasileiros. Anais do I Seminário Nacional: Currículo em Movimento Perspectivas Atuais Belo Horizonte, 2010.

BONDIOLI, A. Construir compartilhando a qualidade: a contribuição das partes interessadas. In: BONDIOLI, A.; SÁVIO, D. (Org.). Participação e qualidade em educação da infância: percursos de compartilhamento reflexivo em contextos educativos. Tradução de Luiz Ernani Fritoli. Curitiba: Ed. UFPR, 2013. p. 25-49.

BRANDALISE, M. A. T. Auto-avaliação de escolas: processo construído coletivamente nas instituições escolares. 2007. 213 f. Tese (Doutorado) - Universidade Católica de São Paulo, São Paulo, 2007.

BRASIL. Constituição. Constituição [da] República Federativa do Brasil. Brasília: Senado Federal, 1988.

BRASIL. Ministério da Educação e do Desporto. Secretaria de Educação Fundamental. Referencial curricular nacional para a Educação Infantil / Ministério da Educação e do Desporto, Secretaria de Educação Fundamental. - Brasília: MEC/SEF, 1998.

BRASIL. Educação Infantil: subsídios para construção de uma sistemática de avaliação. Brasília: MEC/SEB, 2012.2 Disponível em: <portal.mec.gov.br/index.php?option=com_docman\&task...>. Acesso em: 29 jun. 2013.

BRASIL. Indagações sobre Currículo. Currículo e Avaliação - Brasília: Ministério da Educação, Secretaria de Educação Básica, 2007b. 44 p. Disponível em: <http://portal.mec.gov.br/seb/arquivos/pdf/Ensfund/indag5.pdf>. Acesso em: 13 out. 2015.

BRASIL. Indicadores da qualidade na educação infantil. Brasília: MEC/SEB, 2009b. Disponível em: <http://www.portal.mec.gov.br/dmdocuments/indic_educ_infantil.pdf $>$. Acesso em: 5 maio 2013. 
BRASIL. Instituto Nacional de Estudos e Pesquisas Educacionais Anísio Teixeira. Derivado de sinopse estatística da Educação Básica de 2014. Disponível em: http://portal.inep.gov.br/basica-censo-escolar-sinopse-sinopse>. Acesso em: 13 jun. 2015.

BRASIL. Lei n. ${ }^{\circ}$ 8.069, de 13 de julho de 1990. Estatuto da criança e do adolescente. Brasília: Câmara dos Deputados, Coordenação de Publicações, 2001. Disponível em: <www.planalto.gov.br/civil_03/leis/18069.htm>. Acesso em: 14 out. 2012.

BRASIL. Lei n. ${ }^{\circ}$ 9.394, de 20 de dezembro de 1996. Fixa as diretrizes e bases da educação nacional. Diário Oficial [da] República Federativa do Brasil, Brasília, 23 dez. 1996. Disponível em: <portal.mec.gov.br/arquivos/pdf/ldb.pdf>. Acesso em: 16 jul. 2013.

BRASIL. Lei n. ${ }^{\circ}$ 11.494, de 20 de junho de 2007. Dispõe sobre o Fundo de Manutenção e Desenvolvimento da Educação Básica e de Valorização dos Profissionais da Educação FUNDEB e dá outras providências. Diário Oficial [da] República Federativa do Brasil, Brasília, 14 nov. 2007a. Disponível em: <http://www.planalto.gov.br/ccivil_03/_ato20072010/2007/lei/111494.htm>. Acesso em: 19 out. 2012.

BRASIL.Lei n. ${ }^{\circ}$ 13.005, de 25 de junho de 2014. Institui o Plano Nacional de Educação e dá outras providências. Diário Oficial [da] República Federativa do Brasil, Brasília, 26 de junho de 2014b. Disponível em: <http://www.planalto.gov.br/legislacao>. Acesso em: 27 jun. 2014.

BRASIL. MEC. Base Nacional Comum Curricular. Disponível em:<http://basenacionalcomum.mec.gov.br/\#/site/contribua-inicio>. Acesso em: 24 out. 2015.

BRASIL. Ministério da Educação. Conae2014 - o PNE na articulação do sistema nacional de educação. 2014a. Disponível em: <http://conae2014.mec.gov.br/images/pdf/doc_refencia_conae2014.pdf>. Acesso em: 1 set. 2013.

BRASIL. Monitoramento do uso dos indicadores da qualidade na Educação Infantil. Brasília: MEC/SEB, 2011. Disponível em: <portal.mec.gov.br/index.php?option=com_docman\&task...>. Acesso em: 29 jun. 2013.

BRASIL. Resolução CEB $\mathbf{n}^{\mathbf{0}}$ 1, de 7 de abril de 1999. Institui as Diretrizes Curriculares Nacionais para a Educação Infantil. Disponível em: <http://portal.mec.gov.br/cne/arquivos/pdf/CEB0199.pdf>. Acesso em: 18 jul. 2013.

BRASIL. Resolução CNE/CEB no 4, de 13 de julho de 2010. Define Diretrizes Curriculares Nacionais Gerais para a Educação Básica. Disponível em: <http://www.crmariocovas.sp.gov.br/Downloads/ccs/concurso_2013/PDFs/resol_federal_04 _14.pdf>. Acesso em: 13 abr. 2014.

BRASIL. Resolução n..$^{\circ}$ 05, de 17 de dezembro de 2009. Fixa as diretrizes curriculares nacionais para a Educação Infantil. Diário Oficial [da] República Federativa do Brasil, Brasília, 18 dez. 2009a. Seção 1, p. 18.4 Disponível em: <portal.mec.gov.br/index.php?option=com_docman\&task>. Acesso em: 16 jul. 2013. 
CÔCO, V. Trabalhador docente na educação infantil no Espírito Santo. In:BARTOLOZZI, Eliza; OLIVEIRA, D. A.; VIEIRA, L. F. (Org.). O trabalho docente na educação básica: o Espírito Santo em questão. Belo Horizonte: Fino Traço, 2012. p. 59-80.

CÔCO, V.; VIEIRA, M. N. de A.Contextos e práticas de avaliação na Educação Infantil.Revista Nuances: estudos sobre Educação, Presidente Prudente, v. 25, n. 3, p. 36-55, set./dez. 2014.

CÔCO, V.; REIS, M. L. L.; VIEIRA, M. N. A.;LOVATTI, R. R. G.; Zucolotto, V. M.O Plano Nacional de Educação: desafios no campo da educação infantil. EccoS, São Paulo, n. 37, p. $77-$ 92, maio/ago. 2015.

CURY, C. R. J. A Educação Básica no Brasil. Educação \& Sociedade, Campinas, v. 23, n. 80, p. 168-200, set. 2002. DOI: 10.1590/s0101-73302002008000010

FÓRUM PAULISTA DE EDUCAÇÃO INFANTIL. Manifesto indignado do FPEI: avaliar para quê? E para quem?São Paulo, 2012.

HADDAD, L. Currículo para a educação infantil: dilemas, tensões e tendências em debate. In: RODRIGUES, S. A.; GARMS, G. M. Z. (Org.) Temas e dilemas pedagógicos da educação infantil: desafios e caminhos. Campinas: Mercado das Letras, 2012. p. 37-60.

INSTITUTO BRASILEIRO DE GEOGRAFIA E ESTATÍSTICA - IBGE. Censo populacional 2010. Disponível em: <http://censo2010.ibge.gov.br/>. Acesso em: 18 mar. 2014.

KUHLMANN JÚNIOR, M. Histórias da educação infantil brasileira.Revista Brasileira de

Educação, São Paulo, n. 14, maio/jun./jul./ago. 2000. DOI: 10.1590/s141324782000000100002

MACEDO, R. S. Etnopesquisa implicada, currículo e formação. Espaço do currículo, v.5, n.1, p.176-183, jun./dez., 2012.

MAINARDES, J. Abordagem do ciclo de políticas: uma contribuição para a análise de políticas educacionais. Educação \& Sociedade, Campinas, v. 27, n. 94, p. 47-69, jan./abr. 2006. DOI: 10.1590/s0101-73302006000100003

MAINARDES, J.; MARCONDES, M. I. Entrevista com Stephen J. Ball: um diálogo sobre justiça social, pesquisa e política educacional. Educação \& Sociedade, Campinas, v. 30, n. 106, p. 303-318, jan./abr. 2009. DOI: 10.1590/s0101-73302009000100015

MARCONDES, M. I.; MORAES, C. L. Currículo e autonomia docente: Discutindo a ação do professor e as novas políticas de sistemas apostilados na rede pública de ensino. Currículo sem Fronteiras, v. 13, n. 3, p. 451-463, set./dez. 2013.

MOLETTA, A. K.; CAMPOS, N. Intelectuais do GT7 da ANPEd: entre o campo acadêmico e a intervenção no mundo social (1994-1999). Práxis Educativa, Ponta Grossa, v. 10, n. 2, p. 533 557, jul./dez. 2015. DOI: 10.5212/praxeduc.v.10i2.0013

MOVIMENTO INTERFÓRUNS DE EDUCAÇÃO INFANTIL DO BRASIL. Manifesto do MIEIB em defesa da educação infantil. Campo Grande, 2011. Disponível em: 
$<$ http://www.observatoriodaeducacao.org.br/images/pdfs/manisfestomieib.pdf $>$. Acesso em: 15 fev. 2015.

NEVES, V. F. A.; MORO, C. Avaliação na educação infantil: um debate necessário. Estudos em Avaliação Educacional, São Paulo, v. 24, n. 55, p. 272-302, abr./ago. 2013. DOI: 10.18222/ eae245520132727

NÓVOA, A.O regresso dos professores. Pinhais: Melo, 2011.

OLIVEIRA, D. A. As políticas de formação e a crise da profissionalização docente: por onde passa a valorização? Educação em Questão, Natal, v. 46, n. 32, p. 51-74, maio/ago. 2013.

OLIVEIRA, Z. de M. R. de. O Currículo na Educação Infantil: o que propõem as novas Diretrizes Nacionais? Consulta pública, 2010. Disponível em: $<$ http://portal.mec.gov.br/docman/dezembro-2010-pdf/7153-2-1-curriculo-educacao-infantilzilma-moraes/file>. Acesso em: 15 jul. 2015.

OLIVEIRA, D. A.; VIEIRA, L. F. Pesquisa trabalho docente na educação básica no Brasil: sinopse do survey nacional / Universidade Federal de Minas Gerais, Grupo de Estudos Sobre Política Educacional e Trabalho Docente. - Belo Horizonte, 2010. Disponível em: $<$ http://www.gestrado.net.br/images/pesquisas/5/SinopseSurveyNacional_TDEBB_Gestrado. pdf>. Acesso em: 11 jul. 2013.

ROSEMBERG, F. Políticas de educação infantil e avaliação. Cadernos de Pesquisa, São Paulo, v. 43, n. 148, p. 16-21, jan./abr. 2013. DOI: 10.1590/s0100-15742013000100004

RIO DE JANEIRO. Prefeitura Municipal. Manual de Uso do ASQ-3 - guia rápido para aplicação do ASQ-3. Disponível em: <http://200.141.78.79/dlstatic/10112/1132535/DLFE205901.pdf/1.0>. Acesso em: 11 ago. 2013.

SOUSA, S. M. Z. L. Avaliação institucional: elementos para discussão. In: LUCE, Maria Beatriz; MEDEIROS, Isabel Letícia Pedroso de. (Org.). Gestão escolar democrática: concepções e vivências. Porto Alegre: Ed. da UFRGS, 2006. p. 135-142.

SOUSA, S. M. Z. L.; LOPES, V. V. Avaliação nas políticas educacionais atuais reitera desigualdades. Revista Adusp, n. 46, p. 53-59, jan. 2010. Disponível em: <www.adusp.org.br/index.php/.../127-revista-n-46-janeiro-de-2010>. Acesso em: 04 fev. 2014.

VIEIRA, L. F. Apontamentos sobre o documento "Educação infantil: subsídios para a construção de uma sistemática de avaliação". Nuances: estudos sobre Educação, Presidente Prudente, v. 25, n. 3, p. 18-35, set./dez. 2014.

ZANARDINI, J. B. Ontologia e avaliação da educação básica no Brasil (1990-2007). 2008. 208 f. Tese (Doutorado) - Faculdade de Educação, Universidade Federal de Santa Catarina, Santa Catarina, 2008. 